\title{
Body condition status at mating affects gestation length, offspring yield and return rate in ewes
}

\author{
Mehmet Akif Cam ${ }^{1, *}$, Ali Vaiz Garipoglu ${ }^{1, *}$, and Koray Kirikci ${ }^{2, *}$ \\ ${ }^{1}$ Department of Animal Science, Agricultural Faculty, Ondokuz Mayis University, \\ 55200 Atakum, Samsun, Turkey \\ ${ }^{2}$ Department of Animal Science, Agricultural Faculty, Ahi Evran University, 40100 Kirsehir, Turkey \\ *These authors contributed equally to this work. \\ Correspondence: Mehmet Akif Cam (makifcam@omu.edu.tr)
}

Received: 23 February 2018 - Revised: 30 April 2018 - Accepted: 25 May 2018 - Published: 13 June 2018

\begin{abstract}
The present study was planned to determine the effect of ewe body condition score (BCS) and parities on fertility, return rate, gestation length, fecundity, litter size and lamb birth weight. Data were collected from 284 heads of ewes with first to fifth parity and raised at a state farm for three consecutive (2002-2004) years. Teaser rams were used to monitor estrus twice daily in the morning and in the evening from September to October. BCSs and body weights (BWs) were recorded at mating and postpartum. The ewes, at mating time in breeding season and within first $6 \mathrm{~h}$ after the expulsion of fetal membranes, were divided into four groups on the basis of their BCS: thin (BCS $=\leq 2.0 ; n=70 ; 38)$, medium $(\mathrm{BCS}=2.5-3.0 ; n=122 ; 142)$, fat $(\mathrm{BCS}=3.5-4.0$; $n=72 ; 59)$ and very fat $(\mathrm{BCS}=\geq 4.5 ; n=20 ; 17)$. BCSs and BWs of ewes at postpartum were highly correlated with lamb birth weight ( $R=0.486, P<0.01$, and $R=0.130, P<0.05$, respectively). BCSs and BWs of ewes at postpartum had positive effects on lamb birth weight $(Y=3.43 \pm 0.10+0.130+0.047$ ewe body condition score (EBCS), $P<0.01 ; Y=2.92 \pm 0.42+0.018 \pm 0.009$ ewe body weight (EBW), $P<0.05 \mathrm{~kg}$ of lamb birth weight per BCS and kilogram of ewe live weight, respectively). The fertility rate, litter size and fecundity were higher in the medium and fat groups than thin and very fat groups $\left(\chi^{2}=10.607, P<0.01\right)$. The BW and BCS at postpartum affected gestation length positively $(P<0.05)$. Return rate or number of coitus for conception were higher $(P<0.05)$ in thin and very fat groups than medium and fat groups. The data revealed that the ewes with medium and fat body condition $(\mathrm{BCS}=2.5-4.0)$ scores were profitable.
\end{abstract}

\section{Introduction}

Body condition is both a good indicator, which reflects animals' feeding status and general (or nutritional) well-being. Animal productivity has been affected by body fat reserves or body condition score (BCS) (Roche et al., 2009; Vatankhah et al., 2012; Kenyon et al., 2013) either positively or negatively. Additionally, BCS is an important tool for good flock management (Hocking et al., 2011; Van Burgel et al., 2011). Nutrition levels of animals in a herd can be managed via monitoring their BCS (Keinprecht et al., 2016). Farm owners' aims are to gain the most profit from each animal and to have a homogeneous herd. However, these aims cannot be achieved easily due to the competition between animals and genotypic differences in the herd.
Karayaka, a sheep breed reared locally in the Black Sea region, makes up $3 \%$ of total sheep population in Turkey, and it is known to have good-quality meat and low fecundity (Cam et al., 2010). However, the fecundity can be increased via management procedures and breeding strategies. Offspring yield has low heritability, and it was affected by environmental factors (Cam et al., 2017). Accordingly, the body weight and body fat reserve of a ewe can further influence lamb-producing ability and ewes' productivity (Vatankhah and Salehi, 2010; Vatankhah et al., 2012). A sheep farmer who aims to make a greater profit should have more lambs per parity. Good management and well-balanced nutrition of the animals in a farm results in a good body fat reserve and thus early development and early production. 
The reproduction-related traits (return rate, fertility, litter size, dam parity, dam BCS and dam live weight at mating, etc.) are affected by many genetic and environmental factors. Therefore, reproduction results could not be explained by merely one factor, and so the combined influence of factors should be taken into consideration (Corner-Thomas et al., 2012; Corner et al., 2013).

An animal's skeletal structure and fattening state are the main factors which determine its body weight. Therefore, body weight alone is unable to define an animal's body fat reserve state (Vatankhah et al., 2012). There are some young animals with lower body weights (BWs) and higher BCSs as well as some older animals with higher BWs and lower BCSs. On the other hand, the BW and BCS of an animal are affected by parity. The parity affects an animal's reproductive traits such as offspring yield, fertility rate and kilograms born/ewes conceived (Abdel-Mageed and Abd El-Gawad, 2015; González-García et al., 2015).

Although there were more data about the fact that the body condition status of ewes, especially in the third part of gestation, has a positive effect on mammary gland regeneration and correspondingly more milk yield after postpartum and also decreases lamb deaths due to undernutrition of lambs (Kenyon et al., 2013), there were not enough data related to the influences of BCS, parity and live body weight at mating on litter size, return rate and fecundity. Therefore, in this study, we aimed to determine the effect of BCS, parity and body weight of Karayaka ewes, partly reared under extensive conditions, at mating time on litter size, fecundity, lamb birth weight, the number of cycles for conception in each mating periods, conception rates and gestation length.

\section{Materials and methods}

All experimental procedures and animal management were performed according to the Animal Care and Use Guidelines of Ondokuz Mayis University of Local Ethical Committee.

\subsection{Data set}

In the present study, a total of 284 data collected from Karayaka ewes (2-6 years old, first to fifth parity) in 2002 (74 heads), 2003 (85 heads) and 2004 (125 heads) raised at the experimental farm $\left(41^{\circ} 35 \mathrm{~N}\right)$ of the Ondokuz Mayis University, Samsun, Turkey. Furthermore, a total of 290 data were collected from lambs in 2002 (77 heads), 2003 (88 heads) and 2004 (125 heads). The ewes were divided on the basis of their BCSs into four groups: thin, $(\mathrm{BCS}=\leq 2.0$; $n=70$ (at mating) and $n=38$ (at postpartum)), medium (BCS $=2.5-3.0 ; n=122$ (at mating) and 142 (at postpartum)), fat (BCS $=3.5-4.0 n=72$ (at mating) and 59 (at postpartum)), and very fat $\mathrm{BCS}=>4.0 ; n=20$ (at mating) and 17 (at postpartum)) at mating time in breeding season and at postpartum within at least $6 \mathrm{~h}$ after the expulsion of fetal membranes (on a scale of 1 to 5,1 is emaciated and 5 is ex- tremely fat; the scale has increments of 0.5) (Gallego-Calvo et al., 2014). Thin and very fat groups were termed extreme groups.

Body condition scoring was performed by lumbar palpation performed by a single, skilled person. Body weights of the ewes were determined by weighing them on scales $( \pm 50 \mathrm{~g})$ at mating and postpartum within at least $6 \mathrm{~h}$ after the expulsion of fetal membranes.

All the lambs were weighed at least $6 \mathrm{~h}$ after the expulsion of fetal membranes and ear-tagged after birth, and then pedigree, birth type and gender were recorded. The number of lambs and the litter size, fertility rations and gestation lengths of ewes based on BCSs at mating and postpartum were calculated as the results of lambing in farm records, and return rates were also determined the same way.

Table 1 summarizes the ewe live weights and body condition scores at the beginning of mating periods and at term periods. The herd body condition frequencies are shown in Fig. 1.

In lambing periods, ewes were observed more than once daily and the lambing ewes were separated from the herd and housed in individual lambing pens. The genders, birth types, birth weights and mother ear numbers, etc., related to the bearing lambs were recorded. Lambing difficulty was assessed according to the method suggested by Dawson et al. (1999).

Parities were determined from the ear-tagged records in the farm pedigree record lists.

\subsection{Animal management}

Throughout the year, the ewes were maintained on pasture if weather conditions were suitable. However, the ewes were given grass hay (approximately $1500 \mathrm{~g}$, per animal per day, containing $7.5 \%$ crude protein $(\mathrm{CP}), 7.3 \mathrm{~J} \mathrm{ME} / \mathrm{kg} \mathrm{DM}$ joules of metabolizable energy per kilogram of dry matter) and compound feed (approximately $350 \mathrm{~g}$, per animal per day, containing $16.3 \% \mathrm{CP}, 12.5 \mathrm{MJ} \mathrm{ME} / \mathrm{kg} \mathrm{DM}$ ) under inadequate pasture during the last 2 months of their gestation. Water and mineral blocks containing trace elements and vitamins were supplied ad libitum.

Lambs were separated from their mothers 2 months before mating and ewes were dried out. The ratio of replacement in the herd was approximately 20-25\%. Ewes were maintained in the herd for five parities.

Rams were selected from the same private Karayaka sheep flocks and they were kept separately from ewes during the breeding season. A ram was used as a breeder for at most 2 years. Breeding rams of 3-4 years old (five heads per year) and teaser rams of 2-5 years old (five heads per year) were fed $450 \mathrm{~g}$ concentrate feed and hay grass (ad libitum) during the mating periods. All of the necessary vaccinations, external and internal parasite treatments were routinely performed by the official veterinary in the farm. 


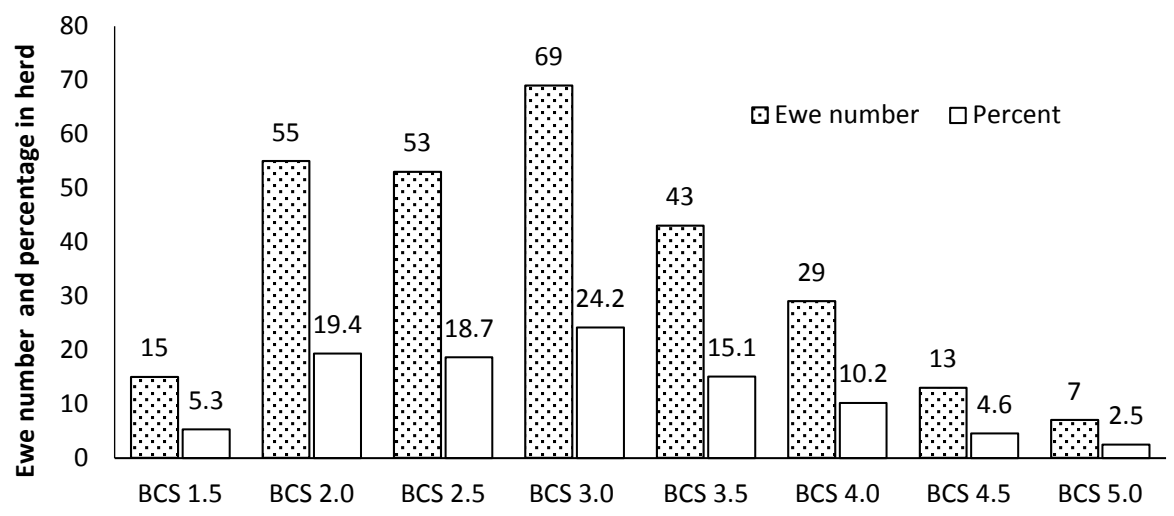

Figure 1. The distribution of ewe number and percentage according to BCS at mating.

Table 1. Body condition scores and body weight status of ewes in three consecutive years.

\begin{tabular}{lrrrrrrr}
\hline Years/ $N$ & EMA & EBWM & EBWP & GL & EBCSM & EBCSP & LBW \\
\hline$(2001-2002) 74$ & 3.26 & $45.61 \pm 0.51$ & $47.57 \pm 0.42$ & $147.82 \pm 0.18$ & 3.08 & 3.07 & $3.91 \pm 0.06^{\mathrm{a}}$ \\
$(2002-2003) 85$ & 3.44 & $45.49 \pm 0.72$ & $47.20 \pm 0.51$ & $147.51 \pm 0.24$ & 2.94 & 2.92 & $3.76 \pm 0.05^{\mathrm{a}, \mathrm{b}}$ \\
$(2003-2004) 125$ & 3.23 & $44.97 \pm 0.49$ & $47.81 \pm 0.37$ & $147.58 \pm 0.21$ & 2.83 & 2.81 & $3.58 \pm 0.06^{\mathrm{b}}$ \\
Overall 284 & 3.30 & $45.29 \pm 0.33$ & $47.54 \pm 0.25$ & $147.62 \pm 0.13$ & 2.93 & 2.90 & $3.72 \pm 0.03^{\mathrm{a}, \mathrm{b}}$ \\
Sign. levels & NS & NS & NS & NS & NS & NS & $P<0.01$ \\
\hline
\end{tabular}

EMA: ewe mean age. EBWM: ewe body weight at mating. EBWP: ewe body weight at postpartum. GL: gestation length. EBCSM: ewe body condition scores at mating. EBCSP: ewe body condition score at postpartum. LBW: lamb birth weight. NS: not significant. ${ }^{\text {a }} \mathrm{b}$ Values with different superscript are significantly different in each column.

\subsection{Matings}

Mating was performed each year for 51 days during October and September (approximately three estrus cycles). Teaser rams were used at a ratio of $1 / 15$ to evaluate estrus twice daily: in the morning at 06:30 and 08:00 local time (LT) and in the evening 18:30 and 20:00 LT in September to October. Ewes within each BCS groups were assigned to rams randomly each year. The estrus ewes determined by the teaser rams were kept in single-sire pens for mating for at least $9 \mathrm{~h}$. After mating, all ewes were stained with red or blue dye so that they were recognized easily for their further estrus return states and all events were recorded. Lamb births took placed within approximately 35 days in each year.

\subsection{Statistical analyses}

No significant differences among the variables (BW and BCS at mating and postpartum) and years were detected; therefore, data were combined. There was a sizeable correlation $(R=0.996, P<0.0001)$ between ewes' parity and ewes' age. Therefore, ewe parity was used instead of ewe age (Kenyon and Blair, 2014). Fertility rate, fecundity, return rate, incidence of dystocia and litter size (prolificacy) were assessed by $\chi^{2}$ test. Binary logistic regression analysis was used to determine of the effect of BCS, parity and ewe weight at mating on fertility and lamb yield. The correlation and regression procedures were used to determine multiple correlation coefficients between lamb birth weight and ewe age, ewe BCS and ewe BW at postpartum. The data of ewe BWs and lamb birth weight were analyzed with a general linear model. The Duncan multiple comparison test was used to determine the differences between means. All statistical evaluations were performed using the SPSS software package version 24.0 for Windows (IBM SPSS Inc, 1989-2016). All tests were conducted at the $P<0.05$ level of significance. The \pm values given after the numbers represent the standard error of the mean.

\section{Results}

Figures 1 and 2 show the distributions of ewes in herds according to their BCSs at the time of mating and postpartum, respectively. The BCS and BWs of ewes related to years are given in Table 1. The lowest and the highest BCS were determined as 1.5 and 5.0 in the herd. Overall, 24.7 and $7.1 \%$ of ewes at mating period and 14.8 and $6.7 \%$ of ewes at postpartum period were in the thin and very fat BCS groups, respectively. Overall, $68.2 \%$ of ewes were in the medium and fat BCS groups at mating and $78.5 \%$ were in these groups at postpartum (Figs. 1 and 2). 
The ratio of very thin $(\mathrm{BCS} \leq 1.5,5.3 \%$ ) to very fat (BCS $\geq 4.5,7.1 \%$ ) groups was low in the flock at mating time. The BCS means at mating and postpartum were 2.93 and 2.90, respectively. This indicates that the nutrition level of herds is adequate. The ratio of ewes with BCSs below 1.5 and of very fat ewes was 3.1 and 6.7, respectively (Fig. 2). There were significant $(P<0.01)$ differences between lamb birth weights related to years.

Binary logistic regression was used to determine the effect of BCS and parity on fertility. The BCS and parity affected fertility $(P<0.05)$. Lamb yield increased $60 \%$ when $\mathrm{BCS} \geq 3$; in any case, the effect of parity was found to be insignificant. An increase of $1 \mathrm{~kg}$ in the weight of ewes at mating led to a $5 \%$ increase in fertility, but this increase was found to be meaningless $(P>0.05)$.

The relationship between the body weight, gestation length and BCS at mating time and the factors such as year and the age of ewes were not significant $(P>0.05$, Table 1$)$. The BCS at mating had a significant effect on fertility rate, gestation length, live weight of ewes at both mating and postpartum, twinning, ewe body condition score (EBCS) at postpartum $(P<0.01)$ and return rate $(P<0.05)$ (Table 2$)$. Similarly, the effects of parity on BCS, infertility, ewe body weight changes, fecundity $(P<0.01)$ and ewe live weight at mating and postpartum, lamb birth weight, gestation length were significant $(P<0.05$; Table 3$)$.

The overall body weights of ewes at postpartum were approximately $2.20 \mathrm{~kg}$ higher than their body weights at mating time (Table 4). Lamb birth weights were not affected by their mothers' body weights and BCSs at mating, but a significant relationship was found between lamb birth weight and ewe body weight at postpartum $(R=0.130$, $P<0.05)$, between lamb birth weight and ewe BCS at postpartum $(R=0.486, P<0.01)$, and between lamb birth weight and ewe parity $(R=0.142, P<0.05)$ at postpartum. With increasing ewe body weight and ewe BCS at postpartum (during the gestation period), lamb birth weight increased $(Y=3.432 \pm 0.10+0.130 \pm 0.047 \mathrm{EBCS}, P<0.01$; $Y=2.922 \pm 0.42+0.0178 \mathrm{EBW} \pm 0.009, P<0.05)$. There was a positive correlation between the mating body weight and postpartum body weight of ewes $(R=0.844, P<0.01)$. Although the number of the ewes exposed to dystocia is low in the herd, one ewe in the thin BCS group and three ewes in the very fat BCS group had dystocia. The difference in the incidence of dystocia between these groups was found to be significant $(P<0.0001)$.

Fecundity was determined as 0.86, 1.04, 1.13 and 1.10 for the BCS groups. Litter size or prolificacy related to ewe body condition scores in the four groups was determined as $\mathrm{BCS}=1.5-2.0,1.05 \pm 0.033$; BCS 2.5-3.0, 1.11 \pm 0.031 ; BCS 3.5-4.0, 1.19 \pm 0.055 ; and BCS 4.5-5.0, 1.29 \pm 0.140 . The fertility rates of thin and very fat groups were lower $(P<0.01)$ than those of medium and fat groups (Table 2$)$.

At mating, the fertility rate, litter size and fecundity were higher in moderate (medium + fat groups) than extreme groups (thin + very fat groups) $\left(\chi^{2}=10.607, P<0.01\right)$. The BCSs and body weights of ewes at postpartum are formed as a result of feeding management during the gestation period. While the litter size increases $(P<0.05)$, the infertility decreases $\left(\chi^{2}=12.282 ; P \leq 0.013\right)$ with increasing parity (Table 3 ).

\section{Discussion}

In this study it was intended to investigate the effects of different BCSs at mating and parities in a state farm herd on fertility, return rate, gestation length and lamb birth weight by using farm records.

Some differences were observed in BCSs between animals reared under the same management conditions. BCS was influenced by both genetical and environmental factors (Abdel-Mageed and Abd El-Gawad, 2015). The differences between the body conditions scores of ewes in this study could be attributed to their status within the hierarchy of the herd, competition among them and physiological differences (milk yield levels, suckling and having twin lamb) (Gonzáles-García et al., 2015). A BCS above 2.5 is recommended at mating (Thompson and Meyer, 1994; Yilmaz et al., 2011; Vatankhah et al., 2012; Van-Burgel et al., 2011). The BCS values of ewes determined in the present study are in accordance with this recommendation $(68.2 \%$ of ewes were in the medium and fat BCS groups; Table 2 and Fig. 2). On the other hand, it is difficult to maintain the ewes at a stable BCS under extensive rangeland rearing conditions due to the difficulty regarding individual nutrition of ewes under these conditions. Our study also showed that BCSs less than 2.5 and higher than 4.0 had a negative effect on fertility rate. It was not only lower BCSs but also higher BCSs that had a harmful effect on fertility rate in this study. There are several possible reasons for the lower fertility rate in the thin and very fat group's ewes. However, the most likely reason is that the gonadotropin hormone releasing mechanism in thin and very fat ewes could be affected by the body energy reserves of ewes (Catunda et al., 2013; Boudreau et al., 2014), which has been found to lead to a decrease in the number of follicles (Faddy, 2000). Meyer (2002) reported that poor BCSs have adverse effects on uterine efficiency, ovulation rate and embryo yield. In the light of this knowledge, we could say that our result from the thin group is in accordance with these findings and, additionally, that a very fat state has a similar effect on fertility.

In our study medium and fat body condition groups had a higher prolificacy and fecundity at mating than thin and very fat groups. According to some studies, the ovulation rate is not influenced by the BCS of ewes (Mitchell et al., 1996; Diskin and Moris, 2008). Our findings can be attributed to the fact that medium and fat groups in our study had a good physiological and balanced endocrine profile so that shedding ova might reside in a suitable uterus environment and 


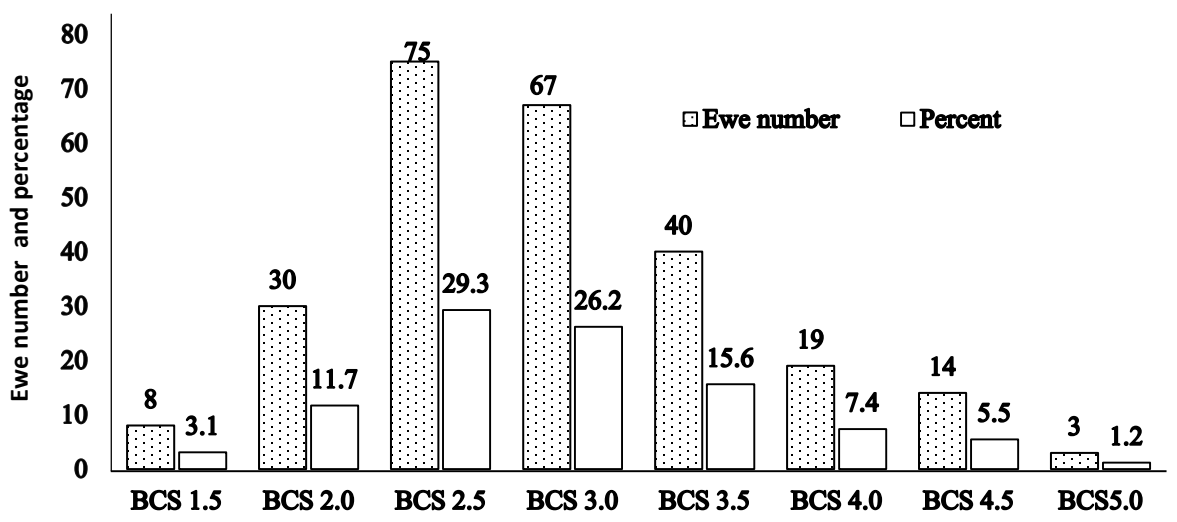

Figure 2. The distribution of ewe number and percentage according to BCS at postpartum.

Table 2. The effects of body condition scores on reproductive performance of ewes at mating.

\begin{tabular}{lrrrrrr}
\hline Traits & \multicolumn{5}{c}{ BCS groups $(n)$} & \\
\cline { 2 - 5 } & $1.5-2.0(70)$ & $2.5-3.0(122)$ & $3.5-4.0(72)$ & $4.5-5.0(20)$ & Overall & $P$ value \\
\hline Fertility & $57 / 70$ & $114 / 122$ & $68 / 72$ & $17 / 20$ & $256 / 284$ & $\leq 0.023$ \\
Rate & $81.42^{\mathrm{a}}$ & $93.44^{\mathrm{b}, \mathrm{c}}$ & $94.44^{\mathrm{c}}$ & $85.00^{\mathrm{a}, \mathrm{b}}$ & 90.14 & $\chi^{2}=9.570$ \\
EBWM & $41.0 \pm 0.50^{\mathrm{a}}$ & $43.4 \pm 0.37^{\mathrm{a}, \mathrm{b}}$ & $49.4 \pm 0.48^{\mathrm{b}, \mathrm{c}}$ & $53.1 \pm 0.95^{\mathrm{c}}$ & $45.0 \pm 0.33$ & $<0.001$ \\
GL & $146.5 \pm 0.21^{\mathrm{a}}$ & $147.2 \pm 0.16^{\mathrm{a}}$ & $148.8 \pm 0.20^{\mathrm{b}}$ & $149.2 \pm 0.51^{\mathrm{b}}$ & $147.6 \pm 0.12$ & $<0.01$ \\
EBWP & $45.1 \pm 0.47^{\mathrm{a}}$ & $46.5 \pm 0.31^{\mathrm{a}}$ & $50.5 \pm 0.33^{\mathrm{b}}$ & $51.8 \pm 1.00^{\mathrm{b}}$ & $45.7 \pm 0.25$ & $<0.001$ \\
BCSM & $1.94^{\mathrm{a}}$ & $2.76^{\mathrm{a}, \mathrm{b}}$ & $3.75^{\mathrm{b}, \mathrm{c}}$ & $4.67^{\mathrm{c}}$ & $2.94 \pm 0.05$ & $<0.01$ \\
Return to & $1.14(10)^{\mathrm{b}}$ & $1.06(7)^{\mathrm{a}}$ & $1.11(8)^{\mathrm{b}}$ & $1.20(4) \mathrm{c}$ & $1.10(29)$ & $<0.05$ \\
estrus $N / n$ & $80 / 70$ & $129 / 122$ & $80 / 72$ & $24 / 20$ & & $\chi^{2}=7.790$ \\
LBW & $3.70 \pm 0.08$ & $3.73 \pm 0.05$ & $3.68 \pm 0.06$ & $3.81 \pm 0.12$ & $3.72 \pm 0.03$ & NS \\
EBCSP & $2.40^{\mathrm{a}}$ & $2.79^{\mathrm{a}, \mathrm{b}}$ & $3.30^{\mathrm{b}, \mathrm{c}}$ & $3.80^{\mathrm{c}}$ & 2.90 & $<0.01$ \\
Twin born & $3^{\mathrm{a}}$ & $13^{\mathrm{a}, \mathrm{b}}$ & $13^{\mathrm{b}, \mathrm{c}}$ & $5^{\mathrm{c}}$ & 34 & $\chi_{(\leq 0.025)}^{2}=9.382$ \\
\hline
\end{tabular}

EBWM: ewe body weight at mating. GL: gestation length. EBWP: ewe body weight at postpartum. BCSM: body condition scoring at mating. LBW: lamb birth weight. $N$ : number of mating. $n$ : number of mating ewes. ${ }^{\mathrm{a}} \mathrm{b}, \mathrm{c}$ Values with different superscript are significantly different in each row.

be implanted into it. On the other hand, parity, BCS and body weight affected each other (Faddy, 2000; Meyer, 2002). Thus, the difference in fecundity and prolificacy cannot be attributed to only one of these factors. Additionally, there are many reports that ovulation rate and litter size were influenced by ewe BW, parity and BCS (Michels et al., 2000). It was reported in some studies (Michels et al., 2000; Yilmaz et al., 2011; González-García and Hazard, 2016) that parity has a strong effect on fecundity and prolificacy or litter size in sheep farming.

The present study showed that animal body fat reserves can affect the return rate and fecundity of ewes. The return rate might be affected by fertility failure or early embryonic deaths for reasons relating to physiological, endocrine and environmental factors (Diskin and Morris, 2008; Catunda et al., 2013). The BCS or body fat reserves are significant effective factors affecting reproductive performance, especially altering or regulating basic hormones that affect the ovulation rate, fertility, and the implantation and maintenance of gesta- tion (Catunda et al., 2013; Boudreau et al., 2014; GonzálezGarcía et al., 2015).

The birth weight of lambs of multiparous ewes was higher than those of primiparous ewes. This finding is agreement with the findings of many researchers (Kenyon and Blair, 2014; González-García et al., 2015; González-García and Hazard, 2016; Griffiths et al., 2016). The lighter birth weights of lambs born to primiparous ewes compared to multiparous ewes can be explained by the fact that the uterus environment of primiparous dams was not fully developed, especially with regard to size (González-García et al., 2015). As a matter of fact, there are many reports about the birth weight differences favoring lambs born to multiparous ewes, and this continues to weaning time (Corner et al., 2013; González-García and Hazard, 2016). On the other hand, it is known that the birth weights of lambs affect BWs and BCSs of ewes at postpartum. The birth weight of lambs is sensitive to a variety of influences (parity, maternal BCS, gestation length, etc.) (Sharma et al., 2012; Griffiths et al., 2016). 
Table 3. The distributions of body weight, body condition scores, litter size and lamb birth weight of ewes according to parity.

\begin{tabular}{|c|c|c|c|c|c|c|}
\hline \multirow[t]{2}{*}{ Variables } & \multicolumn{5}{|c|}{ Parity at mating } & \multirow[t]{2}{*}{$P$ value } \\
\hline & $1(n=46)$ & $2(n=91)$ & $3(n=85)$ & $4(n=42)$ & $5(n=20)$ & \\
\hline EBWM & $39.6 \pm 0.52^{\mathrm{a}}$ & $45.29 \pm 0.37^{\mathrm{b}, \mathrm{c}}$ & $47.47 \pm 0.55^{\mathrm{d}}$ & $47.40 \pm 1.19^{\mathrm{c}, \mathrm{d}}$ & $45.57 \pm 1.10^{b}$ & 0.05 \\
\hline EBWP & $44.35 \pm 0.54^{\mathrm{a}}$ & $47.42 \pm 0.32^{b}$ & $48.86 \pm 0.43^{b}$ & $48.93 \pm 0.72^{\mathrm{c}}$ & $47.04 \pm 0.75^{\mathrm{c}}$ & 0.05 \\
\hline EBCSM & $2.46 \pm 0.064^{\mathrm{a}}$ & $2.87 \pm 0.075^{\mathrm{a}, \mathrm{b}}$ & $3.23 \pm 0.097^{\mathrm{c}}$ & $3.04 \pm 0.144^{\mathrm{b}, \mathrm{c}}$ & $2.73 \pm 0.278^{\mathrm{a}, \mathrm{b}}$ & 0.05 \\
\hline EBCSP & $2.56 \pm 0.068^{\mathrm{a}}$ & $2.82 \pm 0.072^{\mathrm{a}, \mathrm{b}}$ & $3.17 \pm 0.089^{\mathrm{b}}$ & $3.19 \pm 0.159^{b}$ & $2.81 \pm 0.159^{\mathrm{a}, \mathrm{b}}$ & 0.05 \\
\hline Litter size & 1.06 & 1.08 & 1.17 & 1.20 & 1.22 & $>0.05$ \\
\hline Infertility & $11 / 46$ & $7 / 91$ & $6 / 85$ & $2 / 42$ & $2 / 20$ & $\chi^{2}=12.282$ \\
\hline$(\%)$ & 23.91 & 7.69 & 7.05 & 4.76 & 10.00 & $\leq 0.013$ \\
\hline EBWC & $4.61 \pm 0.48^{\mathrm{a}}$ & $2.21 \pm 0.24^{b}$ & $1.40 \pm 0.27^{\mathrm{b}}$ & $1.68 \pm 0.70^{\mathrm{b}}$ & $2.21 \pm 0.67^{\mathrm{b}}$ & $<0.001$ \\
\hline LBW & $3.60 \pm 0.87^{\mathrm{a}}$ & $3.71 \pm 0.056^{\mathrm{a}, \mathrm{b}}$ & $3.71 \pm 0.057^{\mathrm{a}, \mathrm{b}}$ & $3.84 \pm 0.081^{b}$ & $3.82 \pm 0.120^{\mathrm{b}}$ & 0.05 \\
\hline GL & $146.52 \pm 0.335^{\mathrm{a}}$ & $147.53 \pm 0.215^{\mathrm{a}, \mathrm{b}}$ & $147.61 \pm 0.462^{b}$ & $147.78 \pm 0.311^{b}$ & $148.13 \pm 0.221^{b}$ & 0.05 \\
\hline Return to & $7 / 46$ & $9 / 91$ & $5 / 85$ & $3 / 42$ & $5 / 20$ & $\chi^{2}=8.843$ \\
\hline estrus $(\%)$ & 15.22 & 9.89 & 5.88 & 7.14 & 25.00 & $\leq 0.065$ \\
\hline \multirow[t]{2}{*}{ Fecundity } & $37 / 46$ & $91 / 91$ & $92 / 85$ & $48 / 42$ & $22 / 20$ & $\chi^{2}=12.433$ \\
\hline & 0.80 & 1.00 & 1.08 & 1.14 & 1.10 & 0.01 \\
\hline Twin born & 2 & 7 & 13 & 8 & 4 & $>0.05$ \\
\hline
\end{tabular}

EBWM: ewe body weight at mating. EBWP: ewe body weight at postpartum. EBCSM: ewe body condition score at mating. EBCSP: ewe body condition score at postpartum. EBWC: ewe body weight changes between mating and postpartum according to ewe parity. $n$ : number of mating ewes. GL: gestation length. LBW: lamb birth weight. ${ }^{\text {a, }}$ b, c, d Values with different superscript are significantly different in each line.

Table 4. Body weights, gestation lengths and lamb birth weights of ewes related to BCS at postpartum.

\begin{tabular}{|c|c|c|c|c|c|c|c|}
\hline $\mathrm{EBCSP} / n$ & EBWP & GL & LBW & Max-min & \multicolumn{2}{|c|}{ Dystocia } & BW change \\
\hline $1.5-2.0(38)$ & $45.3 \pm 0.64^{\mathrm{a}}$ & $147.1 \pm 0.64^{\mathrm{a}}$ & $3.51 \pm 0.10^{\mathrm{a}}$ & $2.2-4.7$ & 1 & $1 / 38$ & $2.42 \pm 0.48$ \\
\hline $4.5-5.0(17)$ & $52.2 \pm 0.92^{\mathrm{d}}$ & $148.5 \pm 0.92^{\mathrm{b}}$ & $4.11 \pm 0.19^{b}$ & $2.1-5.1$ & 3 & $3 / 17$ & $1.56 \pm 0.78$ \\
\hline $2.5-3.0(142)$ & $46.9 \pm 0.28^{b}$ & $147.4 \pm 0.28^{\mathrm{a}}$ & $3.77 \pm 0.04^{\mathrm{a}, \mathrm{b}}$ & $2.1-5.1$ & 0 & & $2.46 \pm 0.25$ \\
\hline $3.5-4.0(59)$ & $49.7 \pm 0.47^{\mathrm{c}}$ & $148.3 \pm 0.47^{b}$ & $3.79 \pm 0.07^{\mathrm{a}, \mathrm{b}}$ & $2.5-5.1$ & 1 & $1 / 201$ & $1.75 \pm 0.41$ \\
\hline Overall (256) & $47.5 \pm 0.25$ & $147.6 \pm 0.12$ & $3.75 \pm 0.034$ & & 5 & & $2.20 \pm 0.19$ \\
\hline$P$ value & $<0.001$ & $<0.001$ & $<0.01$ & & & $\begin{array}{l}0001 \\
24.806\end{array}$ & NS \\
\hline
\end{tabular}

EBCSP: ewe body condition score at postpartum. EBWP: ewe body weight at postpartum. LBW: lamb birth weight. GL: gestation length. $n$ : number of mating ewes. ${ }^{a, b, c}$ Values with different superscript are significantly different in each column.

Additionally, it is known that a fetus gains most of its weight during the last 2 months of gestation (McGregor, 2016; Ahmed et al., 2016). The gestation length of primiparous ewes was lower than those of multiparous ewes. This might explain why lambs born to first-parity ewes have a lower birth weight. On the other hand, higher BWs and BCSs during this period might have positive effects on uterine and ovary effectiveness (Meyer, 2002) and the very fat ewes generally give birth to heavier lambs. However, this situation also increases the incidence of dystocia events (Ocak et al., 2005).

In the present study, an increased tendency of dystocia in thin and very fat groups was observed. The incidence of dystocia in the herd was low $(1.95 \%)$, and the highest dystocia incidence determined in the different groups was as follows: thin group $-2.63 \%$; medium group $-0.00 \%$; fat group $1.69 \%$; and very fat group - $17.65 \%$. This increased tendency can be attributed to weaknesses of lambs in the weak group and the very fat condition of lambs in the very fat group. The higher incidence of dystocia in animals with high BCS $(P<0.05)$ can be attributed to the fact that the fat layer surrounding the birth canal does not allow muscles to relax. The very fat state might lead to endocrine disorders (Kenyon and Blair, 2014; Fthenakis et al., 2015; Tripathi et al., 2016).

Body condition of an animal varies depending on breed, its health state, yield level, yield type, physiological state, environmental conditions and genetical state (Yilmaz et al., 2011; Abdel-Mageed and Abd El-Gawad, 2015). The presence of animals with different BCSs in a herd is normal. The percentages of animals with different BCSs partly depends on the quality of a rangeland's vegetation and the possibilities of supplying compound feed.

The higher incidence of return rates of ewes in weak and very fat groups might be associated with conceptus problems. These results show that both overfeeding and underfeeding of animals lead to negative effects on fertility. The 
litter size (the number of lambs born per lambing ewe) of primiparous ewes has been found to be lower than that of multiparous lambing ewes. The result is in agreement with the finding of Dwyer et al. (2005) and Luridiana et al. (2015). The number of lambs born to a mating ewe throughout her life and the number of lambs born to a ewe at a given birth were affected by BCS and parity. It was reported that there was a strong relationship between age and parity in dams in livestock animals (Kenyon and Blair, 2014).

\section{Conclusion}

This study showed that the highest reproductive performances were observed for ewes with BCSs of 2.5 or 4.0. In the present study, it was shown that BCS had minimal effects on birth weights of lambs. Furthermore, the incidence of dystocia was shown to increase in extreme (thin and very fat) groups.

Data availability. Data are available from the corresponding author upon request.

Competing interests. The authors declare that they have no conflict of interest.

Acknowledgements. The authors would like to thank the OMU Agricultural Research and Application Farm staff for animal care and data recording.

Edited by: Steffen Maak

Reviewed by: three anonymous referees

\section{References}

Ahmed, M. H., Salem, A. Z. M., Olafadehan, O. A., Kholif, A. E., Rivero, N., Mariezcurrena, M. A., Camacho, L. M., Elghandour, M. M. Y., Alonso, M. U., and Almaz, A. H. A.: Effect of preand post-partum dietary crude protein level on the performance of ewes and their lambs, Small Ruminant Res., 136, 221-226, 2016.

Abdel-Mageed, I. I. and Abd El-Gawad, M. H.: Effects of breed, parity and post-mating nutrition on reproductive wastage and pregnancy outcomes of Egyptian sheep, Small Ruminant Res., 130, 171-177, 2015.

Boudreau, L., Benkel, B., Astatkie, T., and Rouvinen-Watt, K.: Ideal body condition improves reproductive performance and influences genetic health in female mink, Anim. Reprod. Sci., 145, 86-98, 2014.

Cam, M. A., Olfaz, M., and Soydan, E.: Body measurements reflect body weights and carcass yields in Karayaka sheep, Asian J. Anim. Vet. Adv., 5, 120-127, 2010.
Cam, M. A., Olfaz, M., Kirikci, K., Garipoglu, A. V., and Soydan, E.: Market productivity of single and twin bearing Karayaka Ewes, Academia J. Biotechnol., 5, 84-90, 2017.

Catunda, A. G. V., Lima, I. C. S., Bandeira, G. C., Gadelha, C. R. F., Pereira, E. S., Salmito-Vanderley, C. S. B., Araújo, A. A., Martins, G. A., and Campos, A. C. N.: Blood leptin, insulin and glucose concentrations in hair sheep raised in a tropical climate, Small Ruminant Res., 114, 272-279, 2013.

Corner, R. A., Mulvaney, F. J., Morris, S. T., West, D. M., Morel, P. C. H., and Kenyon, P. R.: A comparison of the reproductive performance of ewe lambs and mature ewes, Small Ruminant Res., 114, 126-133, 2013.

Corner-Thomas, R. A., Hickson, R. E., Morris, S. T., and Kenyon, P. R.: The influences of live weight and body condition score of ewe lambs from breeding to lambing on the live weight of their singleton lambs to weaning, Small Ruminant Res., 119, 16-21, 2012.

Dawson, L. E. R., Carson, A. F., and Kilpatrick, D. J.: The effect of digestible undergradable protein concentration of concentrates and protein source offered to ewes in late pregnancy on colostrum production and lamb performance, Anim. Food Sci. Technol., 82, 21-36, 1999.

Dwyer, C. M., Calvert, S. K., Farish, M., Donbavand, J., and Pickup, H. E.: Breed, litter and parity effects on placental weight and placentome number, and consequences for the neonatal behaviour of the lamb, Theriogenology, 63, 1092-1110, 2005.

Diskin, M. G. and Moris, D. G.: Embryonic and early foetal losses in cattle and other ruminants, Reproduction Domestic Anim., 43, 260-267, 2008.

Faddy, M. J.: Follicle dynamics during ovarian ageing, Mol. Cell Endocrin., 163, 43-48, 2000.

Fthenakis, G. C., Mavrogianni, V. S., Gallidis, E., and Papadopoulos, E.: Interactions between parasitic infections and reproductive efficiency in sheep, Vet. Parasitol., 208, 56-66, 2015.

Gallego-Calvoa, L., Gatica, M. C., Guzmána, J. L., and Zarazaga, L. A.: Role of body condition score and body weight in the control of seasonal reproduction in Blanca Andaluza goats, Anim. Reprod. Sci., 151, 157-163, 2014.

González-García, E. and Hazard, D.: Growth rates of Romane ewe lambs and correlated effects of being mated as hoggets or twotooth ewes on first offspring performance, Livest. Sci., 189, 6369, 2016.

González-García, E., Tesniere, A., Camous, S., Bocquie, F., Barillet, F., and Hassoun, P.: The effects of parity, litter size, physiological state, and milking frequency on the metabolic profile of Lacaune dairy ewes, Domestic Anim. Endocrin., 50, 32-44, 2015.

Griffiths, K. J., Ridler, A. L., Heuer, C., Corner-Thomas, R. A., and Kenyon, P. R.: The effect of liveweight and body condition score on the ability of ewe lambs to successfully rear their offspring, Small Ruminant Res., 145, 130-135, 2016.

Hocking, E. J. E, Copping, K. J., and Thompson, A. N.: Managing the nutrition of twin-bearing ewes during pregnancy using Lifetime wool recommendations increases production of twin lambs, Anim. Prod. Sci., 51, 813-820, 2011.

IBM SPSS Inc: Statistical Package for the Social Sciences, Chicago, IL, 1989-2016.

Kenyon, P. R. and Blair, H. T.: Foetal programming in sheep - Effects on production, Small Ruminant Res., 118, 16-30, 2014. 
Kenyon, P. R., Morris, S. T., Hickson, R. E., Back, P. J., Ridler, A. L., Stafford, K. J., and West, D. M.: The effects of body condition score and nutrition of triplet-bearing ewes in late pregnancy, Small Ruminant Res., 113, 154-161, 2013.

Keinprecht, H., Pichler, M., Pothmanna, H., Huber, J., Iwersena, M., and Drillicha, M.: Short term repeatability of body fat thickness measurement and body condition scoring in sheep as assessed by a relatively small number of assessors, Small Ruminant Res., 139, 30-38, 2016.

Luridiana, S., Mura, M. C., Daga, C., Farci, F., Di Stefano, M. V., Zidda, F., and Carcangiu, V.: Melatonin treatment in spring and reproductive recovery in sheep with different body condition score and age, Anim. Reprod. Sci., 160, 68-73, 2015.

McGregor, B. A.: The effects of nutrition and parity on the development and productivity of Angora goats: 1 . Manipulation of mid pregnancy nutrition on energy intake and maintenance requirement, kid birthweight, kid survival, doe live weight and mohair production, Small Ruminant Res., 145, 65-75, 2016.

Meyer, H. H.: Genetic and Environmental Impacts on Prenatal Lamb Loss, Sheep Goat Res. J., 17, 11-14, 2002.

Michels, H., Decuypere, E., and Onagbesan, O.: Litter size, ovulation rate and prenatal survival in relation to ewe body weight: genetics review, Small Ruminant Res., 38, 199-209, 2000.

Mitchell, L. M., King, M. E., Aitken, R. P., and Wallace, J. M.: Effect of mating season and body condition on ovulation, fertilization and pregnancy rates in crossbred ewes, Theriogenology, 45, p. 293, 1996.

Ocak, N., Cam, M. A., and Kuran, M.: The effect of high dietary protein levels during late gestation on colostrum yield and lamb survival rate in singleton-bearing ewes, Small Ruminant Res., 56, 89-94, 2005.
Roche, J. R., Friggens, N. C., Kay, J. K., Fisher, M. W., Stafford, K. J., and Berry, D. P.: Body condition score and its association with dairy cow productivity, health, and welfare, J. Dairy Sci., 92, 5769-5801, 2009.

Sharma, R. K., Blair, H. T., Jenkinson, C. M., Kenyon, P. R., Cockrem, J. F., and Parkinson, T. J.: Uterine environment as a regulator of birth weight and body dimensions of newborn lambs, J. Anim. Sci., 90, 1338-1348, 2012.

Thompson, J. M. and Meyer, H.: Body condition scoring of sheep, available at: http://ir.library.oregonstate.edu/xmlui/ bitstream/handle/1957/14303/ec1433.pdf (last access: 22 February 2018), 1994.

Tripathi, S. K., Farman, M., Nandi, S., Mondal, S., Gupta, P. S. P., and Grish, K. V.: In vitro culture of oocytes and granulosa cells collected from normal, obese, emaciated and metabolically stressed ewes, Anim. Reprod. Sci., 170, 83-89, 2016.

Van Burgel, A. J., Oldham, C. M., Behrendt, R., Curnow, M., Gordon, D. J., and Thompson, A. N.: The merit of condition score and fat score as alternatives to live weight for managing the nutrition of ewes, Anim. Prod. Sci., 51, 834-841, 2011.

Vatankhah, M. and Salehi, S. A.: Genetic and non-genetic factors affecting Lori-Bakhtiari ewe body weight and its relationship with productivity, Small Ruminant Res., 94, 98-102, 2010.

Vatankhah, M., Talebi, M. A., and Zamani, F.: Relationship between ewe body condition score (BCS) at mating and reproductive and productive traits in Lori-Bakhtiari sheep, Small Ruminant Res., 106, 105-109, 2012.

Yilmaz, M., Altin, T., Karaca, O., Cemal, I., Bardakcioğlu, H. E., Yilmaz, O., and Taskin, T.: Effect of body condition score at mating on the reproductive performance of Kivircik sheep under an extensive production system, Tropical Animal Health Production, 43, 1555-1560, 2011. 